This item was submitted to Loughborough's Research Repository by the author.

Items in Figshare are protected by copyright, with all rights reserved, unless otherwise indicated.

\title{
Behavioural operational research: returning to the roots of the OR profession
}

PLEASE CITE THE PUBLISHED VERSION

http://dx.doi.org/10.1016/j.ejor.2015.10.034

\section{PUBLISHER}

(c) Elsevier and Association of European Operational Research Societies

\section{VERSION}

AM (Accepted Manuscript)

\section{PUBLISHER STATEMENT}

This work is made available according to the conditions of the Creative Commons Attribution-NonCommercialNoDerivatives 4.0 International (CC BY-NC-ND 4.0) licence. Full details of this licence are available at: https://creativecommons.org/licenses/by-nc-nd/4.0/

\section{LICENCE}

CC BY-NC-ND 4.0

\section{REPOSITORY RECORD}

Franco, L. Alberto, and Raimo P. Hamalainen. 2019. "Behavioural Operational Research: Returning to the Roots of the OR Profession". figshare. https://hdl.handle.net/2134/21574. 


\title{
Editorial
}

\section{Behavioural operational research: Returning to the roots of the OR profession}

\author{
L. Alberto Franco ${ }^{\mathrm{a}}$, Raimo P. Hämäläinen ${ }^{\mathrm{b}}$ \\ ${ }^{a}$ School of Business and Economics, Loughborough University, Leicestershire LE11 3TU, UK \\ ${ }^{b}$ Systems Analysis Laboratory, Aalto University, P.O. Box 11100, 00076 Aalto, Finland
}

\section{Introduction}

We witness and welcome the resurgence of interest in the study of behavioural issues in the conduct of operational research (OR). The use of the term 'resurgence' is deliberate: the consideration of human factors in models and model-supported processes can be traced back to debates in the 1960s and 1970s (e.g. Ackoff, 1977; Churchman, 1970; Dutton \& Walton, 1964). However, whilst the socially situated nature of OR in practice has long been recognised (e.g. Keys, 1997), it was not until the wave of recent activity triggered by Hämäläinen et al's (2013) paper in this journal that the role and impact of behaviour in OR practice regained centrality in academic and practitioners circles alike.

The very high number of proposals and submissions to this special issue shows that there is indeed widespread interest in this area, which only now has found a home base platform by the introduction of the term behavioural OR (BOR) (Hämäläinen et al., 2013). Events such as the 2014 IFORS and 2015 EURO conference streams on BOR, the creation of a BOR national interest group sponsored by the UK OR Society, and the launch of a BOR website portal hosted by Aalto University (bor.aalto.fi) are all a clear testimony of the revival of the BOR agenda within our community.

We begin this editorial with a definition of BOR and a justification for doing BOR. Next, we draw on theories of practice to propose three key categories that provide alternative analytic foci and points of entry to BOR studies: OR actors, OR praxis and OR methods. We conclude the editorial by reviewing the contributions of the articles published in the special issue.

\section{What is behavioural OR?}

In many other fields, attention to the study of behavioural issues becomes prominent when the theoretical core of the discipline has reached maturity. This has happened in economics, finance, accounting and strategic management, as well as in cognate disciplines such as operations management, decision and game theory and environmental modelling (Bendoly, Van Wezel, \& Bachrach, 2015; Birnberg, Luft, \& Shields, 2007; Bruce, 2010; Camerer, 2003; Camerer \& Lowenstein, 2003; Hämäläinen, 2015; Powell, Lovallo, \& Fox, 2011; Von Winterfeldt \& Edwards, 1986). The development in operational research is similar and thus the current interest in BOR should not be surprising. Furthermore, as the discipline is concerned with improving human problem solving and decision making in practice, the shift towards a behavioural focus is inevitable.

As interest in developing the BOR agenda continues to gather momentum, it is important to address the question of what constitutes the domain of BOR. However, although definitions are always necessary to operationalise and study a phenomenon, we feel that it would be inappropriate to offer a single definition that would hinder how OR academics and practitioners interpret and empirically

\footnotetext{
${ }^{1}$ Corresponding author telephone +44 (0)1509 228 004; email: l.a.franco@lboro.ac.uk
} 

profession. European Journal of Operational Research (2015), doi: 10.1016/j.ejor.2015.10.034

investigate behavioural issues in OR. Instead, we introduce two main streams of BOR studies that have generated attention in the field. The first stream has a long history within academic OR, and concentrates on the use of OR methods to model human behaviour in complex settings. The second stream is receiving increasing attention by both OR academics and OR practitioners, and investigates the role and impact of behavioural aspects related to the use of OR to support problem solving and decision making. While different in focus, both streams share the common goal of deploying ORsupported processes with a view to designing or improving organisational systems and operations.

We believe that work on both streams is important to advance the BOR agenda, thus allowing for many possible research topics worth pursuing. Our belief is based on two assumptions. First, we assume that work on either stream will be grounded in behavioural theories or frameworks drawn from the social sciences and organisation studies, which can help advance explanations of how ORsupported processes are actually performed in practice, and with what effect. However, we do not advocate any particular behavioural theory or framework. Nor we favour a specific research methodology to conduct BOR studies, as is the case in economics and finance. For example, we view experimental studies using psychological theories to study OR-supported processes as just one possible way of doing BOR. Second, we assume that BOR studies will go beyond description and be concerned with improving OR in practice, including the responsible use of OR methods. In short, we encourage operational researchers to use a range of theories and research methodologies in order to produce the knowledge required to deliver the best possible problem solving and decision support for individuals, groups and organisations.

Why do we need more understanding about behavioural issues in OR? The cornerstones of operational research are naturally the optimization and systems modelling methods that have been developed, in which attention to behaviour might not seem a primary concern. However, behavioural aspects become relevant when transferring these methods to practical use. It is not enough to have a technically correct and valid model; we also need designed OR intervention processes in which human aspects have been taken into account.

\section{OR actors, OR praxis and OR methods}

There is long standing tradition in decision analysis and system dynamics of doing research that models behaviour, as well as research that investigates the behavioural consequences of model use (for comprehensive treatments, see French, Maule, \& Papamichail, 2009; Sterman, 2000). More recently within mainstream OR, examples of how behaviour can be incorporated in OR models, together with studies of how behaviour affects, or is affected by OR model-supported processes are beginning to appear (e.g. Ackermann \& Eden, 2011; Amini, Wakolbinger, Racer, \& Nejad, 2012; Brailsford \& Schmidt, 2003; Franco, 2013; Hämäläinen et al., 2013; Morton \& Fasolo, 2009; Ormerod, 2014; Rouwette, Korzilius, Vennix, \& Jacobs, 2011; White, 2009). These studies encompass a wide range of topics and research methodologies that suggests a heterogeneous BOR field. In this section we draw on the practice traditions within the social sciences (Reckwitz, 2002; Schatzki, Knorr-Cetina, \& Von Savigny, 2001; Turner, 1994) and organisation studies (Jarzabkowski, Balogun, \& Seidl, 2007; Nicolini, 2012; Whittington, 2006), and adopt the basic vocabulary of OR actors, OR praxis, and OR methods as an organising framework that highlights different unit of analysis and entry points for the conduct of BOR studies.

OR actors refer to those individuals who design, implement and influence OR-supported processes. These are not just operational researchers who are at the centre of OR work, but also others who engage in OR-related activity either as clients, sponsors, participants or users. All these can be seen as OR actors whose behaviour is critical to the success or failure of OR interventions and projects. From a BOR perspective, OR actors are thus an obvious unit of analysis and point of entry into the field. Currently, there a number of studies that focus on particular types of actors such as expert or novice modellers (Tako \& Robinson, 2010; Tavella \& Papadopoulos, 2015; Willemain, 1994, 1995; 

profession. European Journal of Operational Research (2015), doi: 10.1016/j.ejor.2015.10.034

Willemain \& Powell, 2007), but there is still little work examining how other types of OR actors contribute to shape OR-supported processes, with few exceptions (e.g. O'Brien, 2015; Ormerod, 2014).

What OR actors actually 'do' in practice is OR praxis, namely, all the various streams of actual OR activity carried out by OR actors. Although OR praxis involves dynamic flows of activity taking place at different organisational levels (Mitchell, 1993), behavioural aspects of OR praxis are most visible within specific 'episodes' (cf. Luhmann, 1995) of OR-related activity such as meetings, presentations and workshops of varying duration, frequency and sequence. The domain of OR praxis is thus comprised of all the activities that are consequential for the conduct of OR work, and can be a fruitful arena for BOR studies. Some progress has been made with regards to the praxis of OR-supported workshops (Franco \& Rouwette, 2011; Horlick-Jones \& Rosenhead, 2007; Shaw, Ackermann, \& Eden, 2003; Slotte \& Hämäläinen, 2015; Tavella \& Franco, 2015), but more work is needed in this area.

Finally there are the methods that OR actors typically draw on in their praxis. OR methods refer to standardised types of behaviour that include routines for building and using models, approaches to communicating model results, and norms and procedures for intervention design, problem solving and decision making. OR methods provide the resources through which OR actors are able to interact in order to accomplish OR work, and thus also include specific OR techniques and tools as they can become a source of guidance for actual problem solving and decision making activity. Despite their standardisation, OR methods can be used in diverse and variable ways, and adapted to the uses to which they are put by OR actors (Franco, 2013; Howick \& Ackermann, 2011). They are thus an obvious area for studying behavioural issues in OR practice. For example, we might study what behavioural theories inform the design of OR methods, what OR methods are used, how use changes over time, and the consequences of different use patterns for shaping OR praxis.

BOR studies do not need to address all three categories of OR actors, OR praxis and OR methods at the same time. The categories presented here are discrete and it is possible to bracket one or more categories in any one study. In practice, however, it would be difficult to focus on one without paying attention to the others. We adopt a pragmatic position and accept that whilst any BOR study will inevitably link all three, empirically there will be different dominant areas of focus. For example, studies may foreground OR methods by focusing on modelling behaviour (e.g. Brailsford, Harper, \& Sykes, 2012), whilst backgrounding OR actors and OR praxis. More ambitious studies might bring to the fore more than one focus, for example, the interconnections between OR actors and OR methods (e.g. Monks, Robinson, \& Kotiadis, 2014), whilst leaving the praxis dimension in the background.

\section{Introduction to the articles in the special issue}

Our call for papers attracted 86 proposals, which demonstrated the scope and relevance of the BOR field, as well as its heterogeneous nature. The decision to reject specific proposals at desk level, or request them to be developed into full papers prior to send them for review, was based largely on a clear and significant consideration of behavioural issues in modelling, the design and use of ORsupported processes, or both. Invited full submissions went through several iterations, at each stage further developed and refined with the assistance of reviewers drawn from across different domain within OR. In some cases, we redirected manuscripts to the regular EJOR submission process.

This special issue opens with four essays that reflect on the relevance and promise of BOR. Brocklesby (2015) adopts a process lens to offer a carefully crafted argument about the need to study the intersection between behaviour and modelling. He then explores ways in which the BOR research agenda can be implemented, placing particular emphasis on how relevant social theories can inform research on, and communication about, the complexities of OR professional practices. Similarly, Becker (2015) highlights the need to conduct research into the relationship between behaviour and the use of OR in practice, grounded in appropriate theoretical concepts, all with a view to inform and 

profession. European Journal of Operational Research (2015), doi: 10.1016/j.ejor.2015.10.034

improve OR praxis. His essay also argues that for behavioural OR to prosper, we must draw upon alternative definitions of behaviour, embrace multidisciplinary, and ensure close connection with the mathematically oriented subdisciplines within OR. Collectively, these two first essays highlight issues that are important for the development of BOR as a legitimate subdiscipline within OR.

The next two essays provide conceptual frameworks for the study of behaviour in OR. The essay by Luoma (2015) offers a balanced view of the potential benefits of OR. Drawing upon the Carnegie school's tradition of organisational research, 'routine decision making' and 'problem solving' are compared and contrasted to articulate the potential advantages and disadvantages of model-based support. His framework provides useful insights into why OR practitioners may adopt some modelling approaches more readily than others, and points to new opportunities for empirical research and method development within BOR. White's essay (2015) reviews the OR literature using the lens of critical realism to extract a framework that is suggested to advance our understanding of behaviour in OR interventions. The dimensions of the framework (individual/group level; instrumental/symbolic model use; high/low issue divergence) are then suggested for studying behavioural issues in different types of OR intervention. The case of group-based OR interventions is examined further to articulate a range of behavioural-related outcomes (collective efficacy, shared mental models, and collective mind) that can be empirically measured using multiple research methodologies. Luoma's and White's frameworks provide a useful set of theoretical resources for exploring the relationship between behaviour and OR

All the remaining nineteen articles in the special issue make distinct empirical contributions that highlight one or more of the elements in the actors-praxis-methods framework introduced earlier in this editorial. Behavioural issues have been on the forecasting research agenda for a long time, and typically studied under the area of judgemental forecasting. Petropulous, Fildes and Goodwin (2015) examine the effect of big losses on experts' behaviour when performing adjustments to statistical forecasts. The authors show how after a big loss, defined as a judgmental adjustment that significantly decreases the forecasting accuracy compared to the baseline statistical forecast, experts are more likely to make large adjustments in the opposite direction to the previous large error. In addition, the authors demonstrate that by adopting simple strategies (guidance, restrictiveness, Blattberg-Hoch), the negative impacts of this behaviour can be reduced. In their article on the potential value of judgmental adjustments to statistically derived inventory related decisions, Syntetos, Kholidasari and Naim (2015) found that judgmentally adjusting order-up-to (OUT) levels offers a small advantage, and that this advantage is associated with negative adjustments, whilst larger adjustments do not perform well. In addition, the authors demonstrate that when adjustments of OUT levels are accompanied by a justification for the adjustment, then this leads to an improved inventory performance. Overall, these two articles advance our understanding of the behaviour of the OR actor, in this case, the user of statistical forecasts and/or forecasting systems, and how this behaviour can be changed to improve performance.

Siebert and Kunz (2015)'s article also focuses firmly upon the OR actors category. They characterize proactive decision making as a multi-dimensional concept comprised of four proactive skills (systematic identification of objectives; systematic search for information; systematic identification of alternatives; using a decision radar) and two proactive traits (showing initiative; striving for improvement), and posit that individuals high in proactive decision making are both effective decision makers and more satisfied with their decisions. They developed and validated a proactive decision making scale using a very large global data set. By developing this scale, the authors respond to the call for understanding the impact of individual differences on the use of, and satisfaction with, OR methods (Fasolo \& Bana e Costa, 2014; Franco \& Meadows, 2007; Franco, Meadows, \& Armstrong, 2013). 
Please cite as:

Franco, L.A. \& Hämäläinen, R.P. (2015). Behavioural operational research: Returning to the roots of the OR profession. European Journal of Operational Research (2015), doi: 10.1016/j.ejor.2015.10.034

Two papers provide empirical examinations of how OR actors use OR methods. Franco, Rouwette and Korzilius (2015), adopt an experimental approach to examine how groups with different needs for closure use a model to manage conflict while completing a resource allocation decision task. They show that groups high in need for closure experienced more conflict than those with a low need for closure, but used the model to suppress the conflict as opposed to support open discussion. Interestingly, high need for closure groups were more satisfied than their low need for closure counterparts. The authors link this finding to the observation that groups with a high need for closure rejected their models and instead used simpler tools to help them reach a decision. This paper demonstrates the need to account for the effect of individual differences when designing and deploying model-based support. Also adopting an experimental approach, Lahtinen \& Hämäläinen (2015) show the presence of path dependence in the implementation of the Even Swaps method. The notion of path dependence refers to the possibility that two valid but different modelling paths can lead to different modelling outcomes. The causes for this phenomenon in the use of the Even Swaps method are shown to be the accumulation of the measurement stick effect and loss aversion biases. To counter the path dependency phenomenon, the authors suggest design the path of the Even Swaps process so that the effect of its associated biases does not accumulate in favour of any single alternative.

The next two articles survey the published evidence of behavioural-related impacts associated with the use of OR methods. O’Keefe (2015) notes the long standing but thin stream of research into how operational researchers behave when constructing models, and how individuals use such models to make decisions. He undertakes a selective review of experimental behavioural research within OR and cognate disciplines, which suggests a tentative body of knowledge generated by this type of research. The emerging picture is that, to date, experimental research in OR has provided little strong evidence about model creation and use. O'Keefe then suggests three particular areas for further research: experiments where the provision of data is varied, experiments that show how the use of models can help users overcome cognitive biases, and experiment with groups engaged in model creation and use. The review by Scott, Cavana and Cameron (2015) goes beyond experimental evidence but only focuses on the case of group model building (GMB). They found that there is some evidence that GMB is more effective at supporting communication and consensus than traditional facilitation in a range of contexts. They also highlight the increasing evidence of how and why GMB affects users at individual and group levels. Proposed causative mechanisms that have received empirical support are the 'modelling as persuasion' (Rouwette et al., 2011) and 'models as boundary objects' (Black, 2013; Franco, 2013) hypotheses. The authors argue that to benefit behavioural research into the impact of GMB, future research should shift towards the use of multiple cases in applied settings, together with augmenting survey results with more objective measures .

Four papers examine empirically the impact of the use of OR methods on OR actors' behaviour. Three papers examine investigate impacts associated with the use of discrete event simulation models two studies) and system dynamics models (one study). Monks, Robinson and Kotiadis (2015) examine learning during the creation and use of a discrete event simulation (DES) model. Participants in an experimental study were trained to manage queuing problems by varying the degree to which they were involved in creating and using a DES model of a hospital emergency department. They find that people have difficulties in transferring learning from models to analogous problems in other contexts. When learning does take place, this is due to participants having sufficient time to process the structural behaviour of the model, which suggests that some thought should be given to the length of the experimentation phase of practical simulation projects. This study also highlights overconfidence as an issue when those involved in model building attempt to transfer their learning without the aid of a new model. In another DES study, Gogi, Tako and Robinson (2015) consider whether DES models do generate insights. They run an experiment in which participants were placed in three separate groups and given the task to solve using a model with only animation, a model with only statistical results, or using no model at all. Their findings show that there is only some 
Please cite as:

Franco, L.A. \& Hämäläinen, R.P. (2015). Behavioural operational research: Returning to the roots of the OR profession. European Journal of Operational Research (2015), doi: 10.1016/j.ejor.2015.10.034

association between insights generation and using models, particularly those that only included statistical results generated from the models.

The study of system dynamics by Thompson, Howick and Belton (2015) reviews the role of mental models in learning theory to investigate how the model form associates with the timing of learning incidents and the role of social mediation and negotiation in the learning process. In contrast to the experimental methodology adopted in the previous two papers, this research is based on a multiple case study approach comprised of ten system dynamics consulting projects. Analysis of data generated from interviews with the clients and consultants who participated in these projects suggests that mental model change is associated with the occurrence of critical learning incidents. Furthermore, the timing of these incidents appears to be connected to a range of factors including the type of model used, its intended purpose, and the project stage in which it was used.

The fourth paper dealing with the behavioural impacts of OR methods investigates the debiasing role of data envelopment analysis (DEA). The decoy effect refers to the influence of content on decision making. Within the context of efficiency analysis, the decoy effect implies that the inclusion of a dominated decision making unit (the decoy) can influence the choice between non-dominated decision making units, to the extent that the non-dominated unit that is most similar to the decoy will be preferred. Ahn and Vazquez Novoa's (2015) paper reports the results of an experiment to assess whether the decoy effect is present when decision making units are compared against each other, and whether the use of DEA - namely, the incorporation of efficiency scores and existing slacks- can act as a debiasing tool. The results show that adding a dominated decision making unit to the set of decision making units augments the attractiveness of certain dominating units, and that DEA efficiency scores discriminating between efficient and inefficient units serve as an appropriate debiasing procedure. The mention of slacks also contributes to reducing decoy bias, but is also associated with a higher proportion of participants choosing the dominated unit, irrespective of whether slack information is positively or negatively framed. This paper adds to the increasing volume of work regarding the role OR methods in debiasing.

The following two papers are distinct from the ones introduced insofar as they address directly the praxis of OR. Velez-Castiblanco, Brockelsby, and Midgley (2015) present a fine-grained study of how a team of OR practitioners designs an intervention. Using a theory of 'boundary games' as a conceptual framework, the authors show how the configuration of an OR workshop to support a regional council in New Zealand is shaped by communications about boundary judgements. OR actors 'set', 'follow', 'enhance', 'wander outside', 'challenge' and 'probe' boundaries during a discussion about the context and the methods to be used in the workshop. The authors' work offers an alternative view to the normative perspective on OR intervention design that has important implications for OR academics and OR practitioners alike. The second study of OR praxis, by White, Burger and Yearworth (2015), introduces activity theory as a means to characterise problem structuring interventions as a dynamic and complex array of people, objects, artefacts and instruments. They then use activity theory to guide their analysis of a case study drawn from an intervention that explored the use of system thinking for energy efficient planning in a UK city. Using video-recorded material and a comprehensive micro-level coding scheme, the authors show how participants in a problem structuring workshop use mediating artefacts to wrestle with the object of a "zero carbon zone”, and demonstrate how a shared activity system is developed to accommodate contradictions between workshop participants' activity objects (motives). By undertaking fine-grained analyses based on audio and video recordings of actual OR activity, these two studies respond to calls for opening the black box of OR interventions at the micro-level (e.g. Franco, 2014; Franco \& Rouwette, 2011; Tavella \& Franco, 2015), and extend our understanding of OR praxis beyond that currently found within the mainstream OR literature. 

profession. European Journal of Operational Research (2015), doi: 10.1016/j.ejor.2015.10.034

The last six papers foreground the role of OR methods in modelling behaviour in a range of contexts. The paper by Kang, Sawyer, Griffin and Prabhu (2015) addresses the issue of poor adherence behaviour in using continuous positive airway pressure therapy (CPAP) to treat obstructive sleep apnoea. By using Markov models to characterise the dynamics and patterns of patient adherence behaviour, the authors develop a basis for designing cost-effective interventions. Fry and Binner (2015) provide insights into the increasingly important domain of managing evacuations and emergency situations, where the use of models is rapidly expanding. Specifically, the authors study several ways to measure the usefulness of information from social media in the context of emergency evacuations. Behavioural impacts are natural in the encounters of multiple people which are often modelled as games. In these settings strategic behaviour is likely to be present and in economicsrelated problems the question of interest is often to find a regulation policy which maximizes social welfare. The paper by Shi and Lian (2015) on the passengers - taxi service system falls into this category. The problem of designing contracts to coordinate supply chains is also a game theoretical one that has been extensively studied in operations management. Becker-Peth and Thoneman (2015) conducted a series of experiments to investigate behavioural aspects in supply contracts, and developed a new reference-dependent revenue sharing model. Cairns, Goodwin and Wright (2015) develop a new decision-analysis-based modelling framework to analyse stakeholder behaviour in scenario planning. The framework is designed to mitigate biases and to enable a more complex and nuanced engagement with multiple perspectives. Finally, Keller and Katsikopoulos (2015) discuss research in psychological heuristics in relation to OR, surveying empirical evidence on the conditions under which heuristics perform on par or better than more complex decision models. The authors conclude with an empirical demonstration of a very simple heuristic decision rule that could lower casualties in military stability operations.

The articles in this special issue provide clear evidence that progress is being made in developing the BOR agenda. We hope that the range of foci, theories and research methods reported in the articles we feature here will inspire others to engage with BOR. The sustainability of BOR as an area of study will depend on our ability to continually reflect on the role and impact of behaviour in OR practice, and constantly interrogate unchallenged assumptions in OR theory. Ultimately, the overarching promise of the BOR agenda is to enable a move towards better OR methods, improved OR praxis, and increasingly competent OR actors. That is, after all, what a return to the roots of the OR profession is all about.

Guest Editors

\author{
L. Alberto Franco \\ Loughborough University
}

Raimo P. Hämäläinen

Aalto University

\title{
Acknowledgements
}

We would like to thank all the authors who sent their proposals and manuscripts for consideration in this special issue. We were delighted with the response. We are also very grateful to all the referees who helped us in the review process, many of whom were extremely generous with their time. Finally, we are indebted to Robert Dyson, Kate Partner, Randy Van Grunsven, and Gowri Vasanth for their helpful guidance throughout the whole editorial process. 

profession. European Journal of Operational Research (2015), doi: 10.1016/j.ejor.2015.10.034

\section{References}

Ackermann, F., \& Eden, C. 2011. Negotiation in Strategy Making Teams: Group Support Systems and the Process of Cognitive Change. Group Decision and Negotiation, 20(3): 293-314.

Ackoff, R. 1977. Optimization + objectivity = opt out. European Journal of Operational Research, 1(1): 1-7.

Ahn, H., \& Vazquez Novoa, N. 2015. The decoy effect in relative performance evaluation and the debiasing role of DEA. European Journal of Operational Research.

Amini, M., Wakolbinger, T., Racer, M., \& Nejad, M. G. 2012. Alternative supply chain productionsales policies for new product diffusion: An agent-based modeling and simulation approach. European Journal of Operational Research, 216(2): 301-311.

Becker-Peth, M., \& Thonemann, U. W. 2015. Reference points in revenue sharing contracts-How to design optimal supply chain contracts. European Journal of Operational Research.

Becker, K. H. 2015. An outlook on behavioural OR: 3 tasks, 3 pitfalls, 1 definition. European Journal of Operational Research.

Bendoly, E., Van Wezel, W., \& Bachrach, D. G. (Eds.). 2015. The handbook of behavioral operations management: Social and psychological dynamics in production and service settings. New York: Oxford University Press.

Birnberg, J., G., Luft, J., \& Shields, M., D. 2007. Pscyhology theory in management accounting research. In C. Chapman, S., \& A. Hopwood, G. (Eds.), Hanbook of management accounting research: 113-135. Oxford: Elsevier.

Black, L. J. 2013. When visuals are boundary objects in system dynamics work. System Dynamics Review, 29(2): 70-86.

Brailsford, S., \& Schmidt, B. 2003. Towards incorporating human behaviour in models of health care systems: An approach using discrete event simulation. European Journal of Operational Research, 150(1): 19-31.

Brailsford, S. C., Harper, P. R., \& Sykes, J. 2012. Incorporating human behaviour in simulation models of screening for breast cancer. European Journal of Operational Research, 219(3): 491-507.

Brocklesby, J. 2015. The what, the why and the how of behavioural operational research: An invitation to potential sceptics. European Journal of Operational Research.

Bruce, B. (Ed.). 2010. Handbook of behavioral finance: Edward Elgar Publishing.

Cairns, G., Goodwin, P., \& Wright, G. 2015. A decision-analysis-based framework for analysing stakeholder behaviour in scenario planning. European Journal of Operational Research.

Camerer, C. F. 2003. Behavioral game theory: Experiments in strategic interaction: Princeton University Press.

Camerer, C. F., \& Lowenstein, G. (Eds.). 2003. Advances in behavioral economics: Princeton University Press.

Churchman, C. W. 1970. Operations research as a profession. Management Science, 17(2): 37-53.

Dutton, J. M., \& Walton, R. E. 1964. Operational research and the behavioural sciences. Operational Research Quarterly, 15: 207-217.

Fasolo, B., \& Bana e Costa, C. A. 2014. Tailoring value elicitation to decision makers' numeracy and fluency: Expressing value judgments in numbers or words. Omega, 44: 83-90.

Franco, L. A. 2013. Rethinking Soft OR interventions: Models as boundary objects. European Journal of Operational Research, 231(3): 720-733.

Franco, L. A. 2014. Zooming in on problem structuring methods (keynote paper). Paper presented at the OR56 Annual Conference, Royal Holloway, University of London.

Franco, L. A., \& Meadows, M. 2007. Exploring New Directions in Problem Structuring Methods Research: on the role of cognitive style. Journal of the Operational Research Society, 58(12): 1621-1629. 

profession. European Journal of Operational Research (2015), doi: 10.1016/j.ejor.2015.10.034

Franco, L. A., Meadows, M., \& Armstrong, S. J. 2013. Exploring the Impact of Individual Differences in Scenario Planning Workshops: A cognitive style perspective. Technological Forecasting and Social Change, 80(4): 723-734.

Franco, L. A., \& Rouwette, E. A. 2011. Decision development in facilitated modelling workshops. European Journal of Operational Research, 212(1): 164-178.

Franco, L. A., Rouwette, E. A., \& Korzilius, H. 2015. Different paths to consensus? The impact of need for closure on model-supported group conflict management European Journal of Operational Research.

French, S., Maule, J., \& Papamichail, N. 2009. Decision Behaviour, Analysis and Support. Cambridge: Cambridge University Press.

Fry, J., \& Binner, J. M. 2015. Elementary modelling and behavioural analysis for emergency evacuations using social media. European Journal of Operational Research.

Gogi, A., Tako, A. A., \& Robinson, S. 2015. An experimental investigation into the role of simulation models in generating insights. European Journal of Operational Research.

Hämäläinen, R. P. 2015. Behavioural issues in environmental modelling: The missing perspective. Environmental Modelling \& Software, 73: 244-253.

Hämäläinen, R. P., Luoma, J., \& Saarinen, E. 2013. On the importance of behavioral operational research: The case of understanding and communicating about dynamic systems. European Journal of Operational Research, 228(3): 623-634.

Horlick-Jones, T., \& Rosenhead, J. 2007. The Uses of Observation: combining problem structuring methods and ethnography. Journal of the Operational Research Society, 58(5): 588-601.

Howick, S., \& Ackermann, F. 2011. Mixing OR methods in practice: Past, present and future directions. European Journal of Operational Research, 215(3): 503-511.

Jarzabkowski, P., Balogun, J., \& Seidl, D. 2007. Strategizing: The challenges of a practice perspective. Human Relations, 60: 5-27.

Kang, Y., Sawyer, A. M., Griffin, P. M., \& Prabhu, V. V. 2015. Modelling adherence behaviour for the treatment of obstructive sleep apnoea. European Journal of Operational Research.

Keller, N., \& Katsikopoulos, K. V. 2015. On the role of psychological heuristics in operational research; and a demonstration in military stability operations. European Journal of Operational Research.

Keys, P. 1997. Approaches to understanding the process of OR: review, critique and extension. Omega, 25(1): 1-13.

Lahtinen, T. J., \& Hämäläinen, R. P. 2015. Path dependence and biases in the Even Swaps decision analysis method. European Journal of Operational Research.

Luhmann, N. 1995. Social Systems. Stanford, CA: Stanford University Press.

Luoma, J. 2015. Model-based organizational decision making: A behavioral lens. European Journal of Operational Research.

Mitchell, G. 1993. The Practice of Operational Research. Chichester: Wiley.

Monks, T., Robinson, S., \& Kotiadis, K. 2014. Learning from discrete-event simulation: Exploring the high involvement hypothesis. European Journal of Operational Research, 235(1): 195205.

Monks, T., Robinson, S., \& Kotiadis, K. 2015. Can involving clients in simulation studies help them solve their future problems? A transfer of learning experiment. European Journal of Operational Research.

Morton, A., \& Fasolo, B. 2009. Behavioural Decision Theory for Multi-Criteria Decision Analysis: a guided tour Journal of the Operational Research Society, 60(2): 268-275.

Nicolini, D. 2012. Practice theory, work and organization: An introduction. Oxford: Oxford University Press.

O'Brien, F. 2015. On the roles of OR/MS practitioners in supporting strategy. Journal of the Operational Research Society, 66(2): 202-218.

O'Keefe, R. M. 2015. Experimental Behavioural Research in Operational Research: What we Know and What we Might Come to Know. European Journal of Operational Research. 

profession. European Journal of Operational Research (2015), doi: 10.1016/j.ejor.2015.10.034

Ormerod, R. J. 2014. The mangle of OR practice: Towards more informative case studies of 'technical' projects. Journal of the Operational Research Society, 65(8): 1245-1260.

Petropoulos, F., Fildes, R., \& Goodwin, P. 2015. Do 'big losses’ in judgmental adjustments to statistical forecasts affect experts' behaviour? European Journal of Operational Research.

Powell, T., C., Lovallo, D., \& Fox, C., R. 2011. Behavioral strategy. Strategic Management Journal, 32: 1369-1386.

Reckwitz, A. 2002. Towards a theory of social practices: A develpoment in cultural theorizing. European Journal of Social Theory, 5(2): 243-263.

Rouwette, E. A. J. A., Korzilius, H., Vennix, J. A. M., \& Jacobs, E. 2011. Modeling as persuasion: The impact of group model building on attitudes and behavior. System Dynamics Review, 27(1): $1-21$.

Schatzki, T. R., Knorr-Cetina, K., \& Von Savigny, E. (Eds.). 2001. The practice turn in contermporary theory. London: Routledge.

Scott, R. J., Cavana, R. Y., \& Cameron, D. 2015. Recent evidence on the effectiveness of group model building. European Journal of Operational Research.

Shaw, D., Ackermann, F., \& Eden, C. 2003. Approaches to Sharing Knowledge in Group Problem Structuring. Journal of the Operational Research Society, 54(9): 936-948.

Shi, Y., \& Lian, Z. 2015. Optimization and strategic behavior in a passenger-taxi service system. European Journal of Operational Research.

Siebert, J., \& Kunz, R. 2015. Developing and validating the multidimensional proactive decisionmaking scale. European Journal of Operational Research.

Slotte, S., \& Hämäläinen, R. 2015. Decision Structuring Dialogue. EURO Journal on Decision Processes, 3(1-2): 141-159.

Sterman, J. D. 2000. Business dynamics: Systems thinking and modeling for a complex world. Boston, MA: Irwin McGraw-Hill.

Syntetos, A. A., Kholidasari, I., \& Naim, M. M. 2015. The effects of integrating management judgement into OUT levels: In or out of context? European Journal of Operational Research.

Tako, A. A., \& Robinson, S. 2010. Model development in Discrete-Event Simulation and System Dynamics: An empirical study of expert modellers. European Journal of Operational Research, 207(2): 784-794.

Tavella, E., \& Franco, L. A. 2015. Dynamics of group knowledge production in facilitated modelling workshops: an exploratory study. Group Decision and Negotiation, 24(3): 451-475.

Tavella, E., \& Papadopoulos, T. 2015. Expert and novice facilitated modelling: A case of a Viable System Model workshop in a local food network. Journal of the Operational Research Society, 66: 247-264.

Thompson, J. P., Howick, S., \& Belton, V. 2015. Critical Learning Incidents in System Dynamics Modelling Engagements. European Journal of Operational Research.

Turner, S. 1994. The social theory of practices. Cambridge: Polity Press.

Velez-Castiblanco, J., Brocklesby, J., \& Midgley, G. 2015. Boundary games: How teams of OR practitioners explore the boundaries of intervention. European Journal of Operational Research.

Von Winterfeldt, D., \& Edwards, W. 1986. Decision analysis and behavioral research Cambridge: Cambridge University Press.

White, L. 2009. Understanding Problem Structuring Methods Interventions. European Journal of Operational Research, 99(3): 823-833.

White, L. 2015. Behavioural operational research: Towards a framework for understanding behaviour in or interventions. European Journal of Operational Research.

White, L., Burger, K., \& Yearworth, M. 2015. Understanding behaviour in problem structuring methods interventions with activity theory. European Journal of Operational Research.

Whittington, R. 2006. Completing the practice turn in strategy research. Organization Studies, 27: 613-634. 
Please cite as:

Franco, L.A. \& Hämäläinen, R.P. (2015). Behavioural operational research: Returning to the roots of the OR profession. European Journal of Operational Research (2015), doi: 10.1016/j.ejor.2015.10.034

Willemain, T. R. 1994. Insights on Modeling from a Dozen Experts. Operations Research, 42(2): 213-222.

Willemain, T. R. 1995. Model formulation: what experts think about and when. Operations Research, 43(6): 916-932.

Willemain, T. R., \& Powell, S. G. 2007. How novices formulate models. Part II: A quantitative description of behaviour. Journal of the Operational Research Society, 58(10): 1271-1283. 